\title{
Sara Lagi*
}

\section{Georg Jellinek: un pensador político liberal contra el gobierno despótico $(1885-1898)^{* * *}$}

Traducción realizada por:

Augusto Fernando Carrillo Salgado***

Universidad Nacional Autónoma de México (Ciudad de México, México)

\footnotetext{
* Doctora en Historia del Pensamiento Político Europeo por la Universidad de Perugia (Italia). Actualmente es profesora en la Universidad de Turín (Italia).Correo electrónico: sara.lagi@unito. it ORCID: https://orcid.org/0000-0002-2868-1608

** Este artículo fue publicado originalmente como "Georg Jellinek, a Liberal Political Thinker against Despotic Rule (1885-1898)”, Hungarian Historical Review, 5(1), 105-122.

*** Licenciado y maestro en Derecho, con mención honorífica, por la Facultad de Derecho de la Universidad Nacional Autónoma de México (México); especialista como secretario de juzgado (Curso Básico de Secretarios) por la Escuela Judicial del Instituto de la Judicatura Federal (hoy Escuela Federal de Formación Judicial).Correo electrónico: fernando90@comunidad.unam.mx ORCID: https://orcid.org/0000-0001-6107-4917
} 
DOI:

https://doi.org/10.18046/prec.v19.4624 


\title{
Resumen
}

Georg Jellinek es concebido, por lo general, como uno de los representantes más destacados del positivismo jurídico alemán. En este artículo, lo observo no solo como un teórico del derecho, sino también como un pensador político de inspiración liberal. En ese sentido, busco demostrar algunas continuidades y conexiones clave entre los aspectos fundamentales de su teoría jurídica positivista, su visión política de inspiración liberal, así como su estancia en Viena y migración posterior hacia Alemania.

Palabras claves: positivismo jurídico; liberalismo; soberanía; derechos fundamentales; límites al poder.

\begin{abstract}
Georg Jellinek is commonly thought of as one of the most prominent representatives of German legal positivism. In this article, I look Georg Jellinek not only as a legal theorist, but also as a political thinker of liberal inspiration. In this sense, I seek to show some key continuities and connections between the fundamental aspects of his legal, positivistic theory and his political vision of liberal inspiration, and between his stay in Vienna and his move to Germany.
\end{abstract}

Keywords: Legal Positivism; Liberalism; Sovereignty; Fundamental Rights; Limits of Power. 



\section{Georg Jellinek como pensador político: introducción al personaje}

"Esperamos y creemos que la sociedad estará dispuesta a encontrar e implementar algo que pueda preservarla de la bajeza moral y espiritual: el reconocimiento de los derechos de las minorías (Jellinek, 1898, p. 47)”. Esta cita, que podría ser fácilmente atribuida a John Stuart Mill o Benjamin Constant, es tomada del trabajo de Georg Jellinek (1851-1911), un jurista que atrae la atención de los académicos de la historia del pensamiento político. En este ensayo, examino cómo este destacado pensador, ${ }^{1}$ asociado por lo general con el positivismo jurídico alemán y la fundamentación positivista del derecho, puede ser visto y considerado un pensador político de fuerte inspiración liberal.

En tal virtud, analizo el periodo comprendido entre 1885 y $1898,{ }^{2}$ cuando Jellinek publicó una serie de trabajos académicos sobre teoría política y jurídica, así como historia de las ideas políticas, en donde identifica dos problemas capitales (políticos y jurídicos): el de garantizar los derechos fundamentales y el de neutralizar y combatir el gobierno despótico, particularmente la tiranía de las mayorías. Ambas cuestiones, pertenecientes a la tradición del liberalismo europeo. John Gray propone una definición general de liberalismo y destaca que:
común a todas las variantes de la tradición liberal es la concepción definitiva, moderna distintivamente en carácter, del hombre y la sociedad [...]. [E]lla afirma la primacía moral de la persona [...], ella confiere a todos los hombres el mismo estatus moral [...], ella afirma la unidad moral de la especie humana y [...] ella es meliorist en su afirmación de la corregibilidad y mejorabilidad de todas las instituciones sociales. (1986, p. X)

Empero, cuando centramos nuestra atención en el siglo XIX, observamos que el mapa del liberalismo en aquel tiempo era complejo. Cuando empleamos el término, nos estamos refiriendo a una tradición compleja de pensamiento político caracterizada por una variedad de autores, aproximaciones y matices: desde Benjamin Constant hasta Alexis de Tocqueville, desde Madame de

1 La literatura de Jellinek es vasta; véase Schönberg (1997), Breuer (1999), Paulson (ed.) (2000), Kersten (2000), Kelly (2004), Anter (2004), Jounjan (2005), Keller (2005), Kempter (2005), La Torre (2006), Marra (2012), Drüll (2012) y Paz (2013).

2 Jellinek vivió y enseñó en Viena entre 1879 y 1889; en Alemania desde 1889 hasta el día de su muerte acaecida en 1911. 
Staël hasta Sismonde de Sismondi, desde John Stuart Mill hasta Thomas Hill Green, desde el liberalismo alemán céntrico-estatal al liberalismo inglés (Gray, 1986). No obstante, entre esta variedad, podemos identificar algunos principios compartidos clave. Tal y como D. J. Manning explica claramente en su reconocida obra Liberalism:

La libertad que los creyentes liberales del siglo XIX creían que sus antepasados intelectuales habían asegurado al ciudadano; esto es, la libertad que hizo a un hombre ciudadano es la libertad definida por el derecho. Libertad es la creación de restricciones legales. Tiene que ser hallada donde la restricción es justamente impuesta por un Estado de derecho constitucional [...]. Por tanto, la libertad es entendida no como un poder sobre los otros [...], el poder del amo sobre su esclavo. Es la seguridad contra las intromisiones la que hace libre a un hombre. (1976, p. 15)

Ello implica una visión del poder limitado, con el objetivo de proteger las libertades individuales, las minorías y el "dinamismo social" (Manning, 1976). Al mismo tiempo, Manning (1976) nos recuerda que el liberalismo europeo del siglo XIX también enarbolaba que el "individualismo y la energía generada por él estaban amenazados por la tiranía del conformismo social” (p. 18).

Una visión particular del poder y un tipo de miedo comienzan a emerger, verbigracia, en los escritos sobre el pueblo de Constant, Mill y Tocqueville. Constant, en sus reflexiones sobre la Revolución francesa, critica claramente a la corona, así como a las masas conformistas. Tocqueville y Mill denuncian, ambos, la "tiranía de la opinión prevaleciente" y el tema de la "masificación". ${ }^{3}$

Surge, entonces, la duda: ien qué sentido puede ser situado Jellinek dentro del liberalismo del siglo XIX? Él fue un pensador liberal porque creyó en la necesidad de limitar el poder -establecer límites a la potestad gubernamental a través de una constitución y garantías de derecho público con el objetivo de evitar un gobierno despótico- y temió el conformismo social, así como las negativas connotaciones que podría implicar en términos de progreso social y desarrollo.

La atención puesta por Jellinek sobre el problema de limitar el poder y el conformismo social representa un punto de afinidad política e ideológica entre él y pensadores como Constant, Tocqueville y Mill; una afinidad reconocida por 
el propio Jellinek. En otras palabras, incluyendo, por ejemplo, Das System der subjektiven öffentlichen Rechte (Sistema de los derechos públicos subjetivos, 1892), Die allgemeine Staatslehre (Teoría General del Estado, 1900), Die Erklärungen der Menschen und Bürgerrechte (La Declaración de Derechos del Hombre y el Ciudadano, 1895) y Das Recht der Minoritäten (Los Derechos de las Minorías, 1898), él hace referencia a las ideas de estos tres prominentes autores, a los que consideraba importantes puntos de referencia. ${ }^{4}$

Como Manning (1976) escribe, la protección de los derechos fundamentales es central para el liberalismo del siglo XIX; una protección que está basada en la "existencia de restricciones legales." Esto es verdad también para Jellinek, en el sentido de que en todos sus trabajos, y particularmente en su System der subjektiven öffentlichen Rechte, él delinea un sistema de protección jurídica de los derechos fundamentales; una protección jurídica que implica, como explicaré, un camino particular para establecer y justificar conceptualmente los derechos fundamentales a través de una teoría del Estado y el derecho que es positivista.

Esto quiere decir que la inspiración y creencia liberales de Jellinek no pueden ser separadas de sus reflexiones jurídicas sobre la naturaleza y componentes del Estado y el derecho. Es decir, no pueden ser escindidas y aisladas de su idea respecto a que la soberanía pertenece únicamente al Estado. ¿Cómo balancea Jellinek su convicción en un poder que tiene que ser limitado con su idea de soberanía? ¿Qué tipos de conexiones existen entre la inspiración liberal de Jellinek (de acuerdo con la definición del liberalismo del siglo XIX destacada en líneas superiores) y su teoría del positivismo jurídico? Con el propósito de dar respuesta a estas interrogantes, comenzaré con una discusión sobre el periodo que Jellinek pasó en Viena.

\section{Jellinek en el Imperio austrohúngaro (1879-1889): el problema de las minorías}

Georg Jellinek (1851-1911) nació en Leipzig, en el seno de una familia judía de lengua y cultura alemana. Su padre, Adolfo Jellinek, fue un rabino y uno de los más importantes académicos de teología judía de su periodo. Georg Jellinek estudió historia, filosofía y derecho en Alemania. En 1879, devino profesor asociado en la Universidad de Viena, donde vivió e impartió cátedra hasta 1889, cuando decidió renunciar debido al creciente antisemitismo y hostilidades hacia

4 Véase Jellinek (1892 y 1900). 
su persona. En 1891 se trasladó a la Universidad de Heidelberg, donde heredó la cátedra de Derecho Internacional, ocupada con anterioridad por Johann Kaspar Bluntschli (Keller, 2005, p. 22).

En Heidelberg, Georg Jellinek publicó sus trabajos más innovadores y relevantes en doctrina jurídica y teoría del Estado, al tiempo que observaba los cambios políticos de Alemania y la monarquía austrohúngara. Aún después de trasladarse a la Universidad de Heidelberg, continuó estudiando la política y sistema jurídico austrohúngaros. ${ }^{5}$

Jellinek pasó unos años problemáticos e intensos en Viena, donde experimentó de primera mano la compleja realidad política de la monarquía austrohúngara. Aquí, fue afectado particularmente por los numerosos y, a menudo, violentos contrastes políticos que caracterizaban el Consejo Imperial austriaco. Jellinek dedicó a este tema en particular un interesante ensayo intitulado Ein Verfassungsgerichtshof für Österreich (Una Corte Constitucional para Austria, 1885), con el claro propósito de comprender cómo estabilizar de una mejor forma la parte Cisleitania del imperio tras el acuerdo de 1867 (Jellinek, 1885, p. 35). ${ }^{6}$

En su opinión, el componente crucial de los contrastes era la no resuelta cuestión nacional austriaca (Nationalitätenfrage) y, de manera precisa, el hecho de que los partidos austriacos residentes en el Reichstag no eran políticos, sino "nacionales" (Jellinek, 1885, pp. 6-8). ${ }^{7}$

Jellinek (1885) destaca cómo la mayoría de los partidos políticos austriacos encarnaban identidades nacionales precisas y definidas. Detrás de estos partidos había grupos nacionales específicos cuyos intereses conflictuaban a menudo (pp. 6-8). La monarquía austrohúngara era, de hecho, un Estado multinacional, compuesto por alemanes, húngaros, checos, polacos, rutenos, rumanos, italianos, croatas, serbios, eslovacos y eslovenos. Como resultado del acuerdo de 1867,

5 En las décadas de 1880 y 1890, Jellinek escribió y publicó trabajos relevantes sobre la estructura jurídica de la monarquía austrohúngara y, de manera específica, sobre el acuerdo de 1867, que se centraba en la mitad del imperio húngaro. Estos trabajos incluyen: Die rechtliche Natur der Staatenverträge: Ein Beitrag zur juristischen Konstruktion des Völkerrechts (1880); Das rechtliche Verhältnis Kroatiens zur Ungarn: Mit einem Angange das ungarisch-kroatische Ausgleichgesetz enthaltend (1885); Ungarn und die österreichische Verfassung (1897); Ungarisches Staatsrecht (1897).

6 Nota del traductor: Cisleitania era el nombre de la demarcación territorial de la parte austriaca del Imperio austrohúngaro, monarquía bicéfala creada en 1867 y disuelta en 1918.

7 En el uso del término "partido nacional" en oposición al de "partido político", Jellinek (1898, p. 35) afirmó haberse inspirado en el trabajo sobre la cuestión nacional austríaca de Adolf Fischhof (1869). 
el Imperio de Habsburgo devino la monarquía austrohúngara. El acuerdo fue celebrado entre dos Estados que permanecían, respectivamente, unidos como entidades políticas, aunque numerosas personas de diferentes nacionalidades residían en cada uno (Roshwald, 2005, pp. 8-11). ${ }^{8}$

En opinión de Jellinek, los nexos y connotaciones nacionales de los partidos austriacos hicieron la relación entre la minoría y mayoría parlamentaria conflictiva y difícil. El impacto de esta complicada situación sobre el proceso legislativo fue, a menudo, desastroso. En algunas ocasiones una minoría era ultrajada o abusada por la mayoría y, a menudo, la mayoría se oponía vehementemente a iniciativas que habrían otorgado mayores derechos y libertades a la minoría nacional. ${ }^{9}$

De acuerdo con Jellinek (1885), el Consejo Imperial austriaco, en términos legales, el más importante cuerpo legislativo del Imperio, se caracterizaba por una inestabilidad general e "ilegalidad parlamentaria" (Unrecht) (p. 6).

En cuanto profesor de derecho viviendo en Viena, Jellinek identificó al Verfassungsgerichtshof como una solución legal perfecta al problema. La propuesta de Jellinek puede ser mejor entendida y clarificada, si tomamos brevemente en cuenta la tradición político-jurídica de Habsburgo encarnada en la Corte Imperial (Reichgerichtshof).

La Corte Imperial fue oficialmente establecida en 1867 en ocasión del acuerdo que transformó el Imperio austriaco en la monarquía constitucional dual austrohúngara. A la Corte Imperial le fueron dados relevantes facultades y tareas. Esta servía para proteger los derechos de los ciudadanos, aunque no era una corte de casación; esto es, no se encargaba únicamente de la tarea de verificar la interpretación del derecho dado por una corte de jerarquía inferior. La Corte actuaba para neutralizar conflictos potenciales entre los Länder (entidades de la corona) y la autoridad central; también podía supervisar las fronteras entre las autoridades judiciales y administrativas (Lagi, 2012, pp. 257-277). De acuerdo con Jellinek, el reto principal era mejorar la tradicional Corte Imperial austriaca y transformarla en una verdadera Corte Constitucional.

8 Sobre la historia de la monarquía austrohúngara y, particularmente, sobre las complejas relaciones entre sus nacionalidades existe un amplio cuerpo de literatura académica: Evans (1979), Sked (1989), Cornwall (2000 y 2001) y Healy (2004).

9 En 1880, por ejemplo, los diputados austroalemanes del Parlamento Central austriaco opusieron violentamente decretos dirigidos a proporcionar más "derechos lingüísticos" a la comunidad de Bohemia (Stourzh, 1994, pp. 71-74). 
Él hizo un llamado por una Corte Constitucional que pudiera tomar decisiones sobre: 1. conflictos potenciales de competencia entre la legislación ordinaria y constitucional; 2. conflictos de competencia entre la legislación imperial y la normatividad de las entidades de la corona.

De manera más precisa, en lo que respecta al potencial conflicto de competencias entre la legislación ordinaria y constitucional, Jellinek propone claramente un mecanismo jurídico interesante que impactaría, por ejemplo, en uno de los juristas y constitucionalistas más importantes del siglo XX, Hans Kelsen (Lagi, 2007).

El plan de Jellinek para una corte constitucional austriaca reconocía el derecho de una minoría para someter iniciativas a la corte constitucional, a través de las cuales se impugnaran medidas que pudieran ser consideradas contrarias a los derechos y libertades garantizados constitucionalmente a las minorías (Jellinek, 1885, p. 8 y ss.). En tal virtud, el plan de Jellinek para una corte constitucional tenía dos propósitos principales: estaba encaminado a mejorar y reforzar la división de competencias entre las autoridades imperiales y estatales (las cuales Jellinek criticaba por ser completamente opacas e insuficientes) y, más aún, estaba dirigido a defender mejor la constitución de potenciales excesos y transgresiones cometidas por los partidos, órganos parlamentarios y, principalmente, agresión de las mayorías. A través de una mejor protección de la constitución, la protección de las minorías podría ser garantizada mejor y, en opinión de Jellinek, esto era particularmente útil y vital en el contexto complejo del Consejo Imperial austriaco, que estaba caracterizado por las tensiones entre los conflictivos partidos nacionales (Jellinek, 1885, p. 8 y ss.).

El plan de Jellinek para una corte constitucional estaba basado en una desconfianza substancial del cuerpo legislativo, en este caso particular, del Consejo Imperial austriaco, porque la mayoría del cuerpo legislativo podría abusar de su poder al imponer su voluntad en detrimento de la minoría. En ese sentido, la transformación de la Corte Imperial en Corte Constitucional era el único camino, en opinión de Jellinek, para hacer de la monarquía austrohúngara un sólido "Estado constitucional". La idea misma no es, quizá, innovadora, pero un aspecto verdaderamente interesante es observar cuan profundamente político era este plan (Di Suni, 2013, pp. 1-35).

En su trabajo de 1885, Jellinek trata de llegar a una solución legal para un problema eminentemente político. Este consistía en la protección de las 
minorías contra leyes potencialmente antiliberales, buscadas y promovidas por la mayoría. El riesgo representado por una mayoría tiránica fue uno de los temas políticos principales que Jellinek abordó toda su vida. Como se mencionó con anterioridad, en 1891, él se trasladó a Heidelberg para enseñar derecho internacional. En Alemania, continuó reflexionando sobre el problema de las minorías, un problema que experimentó de primera mano en Austria. Si en la monarquía austrohúngara Jellinek se centra, principalmente, en el concepto de las minorías con una connotación étnica y nacional, en Alemania su atención se desplaza a las minorías políticas. Empero, un problema político fundamental subyace: para Jellinek, la protección de las minorías estaba profundamente conectada con la cuestión de garantizar los derechos fundamentales para combatir cualquier forma de gobierno despótico.

\section{Jellinek en Alemania: su visión ius-política y su rechazo al gobierno despótico}

Mientras vivía en Viena, Jellinek fue afectado por los efectos de un parlamento compuesto por diferentes grupos nacionales. Esta realidad, compleja, pudo haber estimulado su interés sobre el problema de las minorías. Jamás olvidó la experiencia austriaca, la cual se encuentra patente en su trabajo Das Recht der Minoritäten, en el que se refiere al componente nacional de los partidos austriacos y la inestabilidad del Consejo Imperial (Jellinek, 1898, pp. 35-36).

Jellinek se centró en las minorías y en la importancia de proveerles una protección concreta y eficiente, reclamada por el liberalismo del siglo XIX. Al igual que muchos otros pensadores liberales destacados, verbigracia, Constant, Tocqueville y Mill, Jellinek consideró la protección de las minorías (tanto políticas como nacionales) como un valor per se, como un prerrequisito de cada sociedad verdaderamente liberal, basada en el respeto por la persona y dignidad humana, así como en el reconocimiento de un "espacio de libertad", que no puede ser transigido, o limitado, por el Gobierno (Jellinek, 1898, pp. 17-40).

En términos de historia del pensamiento político, la preocupación de Jellinek sobre el problema de las minorías y su protección (el cual, a mi juicio, debió estar influenciado por su experiencia en Austria) estuvo profundamente conectado con su idea de Selbstbeschränkung (autolimitación), la cual es el corazón del concepto de su teoría del derecho y el Estado (La Torre, 2007, p. 20). ¿Cuáles fueron las bases políticas de su teoría? ¿Podríamos entender mejor estas bases 
si tomamos en cuenta la definición sobre el liberalismo del siglo XIX dada en líneas superiores? ${ }^{10}$

En 1892, cuando Jellinek estaba en Heidelberg, publicó uno de sus trabajos más importantes: Rechtslehre: Das System der subjektiven öffentlichen Rechte. Por una parte, Jellinek propuso los conceptos clásicos previamente elaborados por Carl Friedrich von Gerber y Paul Laband. ${ }^{11} \mathrm{Al}$ igual que sus predecesores, Jellinek reconoció el poder soberano como perteneciente exclusivamente al Estado. También, reafirmó que únicamente el derecho positivo existe. Al mismo tiempo, se distanció de la doctrina jurídica alemana tradicional, cuando escribió que el Estado se limita a sí mismo al reconocer y garantizar derechos fundamentales (Fabbrini, 2014, pp. 17-18). Para comprender mejor la diferencia entre la concepción jurídica de Jellinek y la de sus predecesores, es importante notar que Gerber consideró a los "derechos individuales como reflexiones 'objetivas' del orden jurídico", y Laband, como derechos definidos, particularmente, como "derechos de libertad" y "normas para el poder estatal, que el Estado se da a sí mismo [...], pero que no establecen derechos subjetivos a los ciudadanos" (Caldwell, 1997, pp. 30-31). En otras palabras, Gerber y Laband, ambos, teorizaron el principio de que los derechos tenían que ser entendidos correctamente y considerados una mera "reflexión" del "sistema jurídico determinado por el Estado".

Al contrario de Gerber y Laband, Jellinek visualizó al Estado como un sujeto capaz de limitarse a sí mismo y, en consecuencia, capaz de garantizar un "espacio de libertad" a los individuos, al establecer "derechos subjetivos" (Jellinek, 1892, p. 67 y ss.). En sus trabajos de teoría jurídica y, más precisamente, en System der subjektiven öffentlichen Rechte, Jellinek elabora un compromiso entre la soberanía del Estado y los derechos fundamentales, al teorizar la protección legal de tales derechos, a través de un acto de autolimitación del Estado que respeta a los individuos. Al hacer esto, Jellinek termina conceptualmente situando uno de los principios capitales del liberalismo del siglo XIX, a través de una teoría positivista del derecho, de acuerdo con la cual aquellos derechos "son protegidos y garantizados dada la existencia del Estado como la soberanía personificada" (Fabbrini, 2014, p. 17).

10 Sobre el concepto de “autolimitación”, véase Kersten (1905 y 2001), Stolleis (1992), Quaglioni (1994) y La Torre (1996).

11 Véanse Von Gerber (1876) y Laband (1876-1882). 
En ese sentido, existe un vínculo profundo entre el espíritu liberal de Jellinek y su doctrina jurídica. Insisto en este punto porque considero que, inclusive, su obra System der subjektiven öffentlichen Rechte (1892) puede ser considerada, desde la perspectiva de la historia del pensamiento político, un trabajo de teoría política, así como un ejemplo excelente del pensamiento y postura política de Jellinek.

Mientras vivía e impartía cátedra en Austria, Jellinek propuso una solución jurídica a un problema eminentemente político. Como podemos apreciar, esta solución particular, consistente en la creación de una corte constitucional, entrañó una innegable y prístina connotación, porque estaba basada en la idea de que las minorías deberían ser respetadas y protegidas. La Corte Constitucional, en la visión de Jellinek, podría ser un antídoto perfecto para la tiranía de las mayorías. En System der subjebtiven öffentlichen Rechte, Jellinek teorizó una base positivista de los derechos fundamentales sustentados en la idea de que el Estado era capaz de autolimitarse. En ambos casos, esto es, en su trabajo sobre la Corte Constitucional y en su obra sobre los subjektiven öffentliche Rechte, Jellinek está convencido, como jurista y pensador político, de que garantizar y preservar los derechos fundamentales implicaba proteger a las minorías e individuos de los abusos del Gobierno despótico.

El papel central interpretado por este tipo de problemas en la producción académica e intelectual de Jellinek está, también, claro en tres de sus escritos, dedicados a la historia de las ideas políticas, publicados en la década de 1890; a saber: Hobbes und Rousseau (Hobbes y Rousseau), Adam in der Staatsrechtslehre (Adán en la Teoría del Estado) y, sobre todo, Die Erklärungen der Menschen und Bürgerrechte (La Declaración de los Derechos del Hombre y el Ciudadano). ${ }^{12}$

En los primeros dos ensayos, Jellinek analiza de manera crítica la tradición del derecho natural, así como sus consecuencias en el pensamiento político liberal de Europa y la organización estatal; mientras que en la tercera de las obras efectúa una comparación directa entre la Bill of Rights y la Déclaration des Droits l'Homme et du Citoyen. A pesar de las diferencias en términos de contenido, todos estos ensayos comparten las mismas interrogantes: iel poder estatal es ilimitado? ¿la mayoría posee un poder absoluto? Ahora examino cómo Jellinek da respuesta a estas dudas cruciales.

12 Jellinek (1895); en este artículo, porque el texto original no está disponible, hago referencia a la traducción italiana: Jellinek (2002). Véase, también, Jellinek (1891, 1893, 1905 y 1970). 
En el primero de los tres trabajos mencionados en líneas superiores, Jellinek destaca la historia de los conceptos jurídicos y políticos con un fuerte énfasis en la tradición del derecho natural. En tanto positivista, Jellinek fue un antiiusnaturalista vehemente. Sin embargo, el aspecto verdaderamente interesante que emerge de sus análisis, particularmente de su trabajo sobre Hobbes und Rousseau, es que él considera al derecho natural como una mera filosofía, una Weltanschauung, un sueño, una visión, carente de una base histórica, caracterizada por sus innegables elementos despóticos. ${ }^{13}$

La tradición del derecho natural ha elaborado y justificado la idea de la organización estatal a través del paradigma del estado de naturaleza y el concepto de contrato, por medio del cual los seres humanos establecerían y legitimarían instituciones políticas. Ante todo, Jellinek critica la tradición del derecho natural como un producto de la imaginación. Él enfatiza que todos los argumentos del derecho natural son falsos, porque estos no están basados en la experiencia histórica. ${ }^{14}$

Sin embargo, en opinión de Jellinek, existe algo aún más peligroso en las enseñanzas concerniente al derecho natural que solamente su fictio. Él creía que ellas inevitablemente "abrirían las puertas" del gobierno despótico, como una consecuencia lógica y necesaria de la idea de que el único camino para abandonar el estado de naturaleza, con todos sus riesgos y ausencia de seguridad, era conferir los derechos fundamentales y libertades a una "tercera persona", el Estado mismo. Desde esta perspectiva de la historia de las ideas políticas e ideologías, no había diferencia entre el autor del Leviathan y el padre del Contrato Social. El uso y legitimación del paradigma del estado de naturaleza conduciría, indefectiblemente, de acuerdo con Jellinek, a un sistema político antiliberal y despótico. ${ }^{15}$

Su crítica a la tradición del pensamiento del derecho natural fue funcional para su fundamentación y legitimación del derecho y el Estado en términos positivistas. Empero, si el iusnaturalismo no era sino una "filosofía", un sueño potencialmente peligroso, icómo podrían explicarse sus vínculos con la Bill of Rights y la Déclaration des Droits l'Homme et du Citoyen?, las cuales parecen haber

13 Estas ideas son expuestas por Jellinek en Die Politik des Absolutismus und Radikalismus.

14 Estos razonamientos son desarrollados por Jellinek en Die Politik des Absolutismus und Radikalismus, así como en Adam in der Staatsrechtlehre.

15 Sobre el particular, véase Jellinek (1970b). 
sido inspiradas en la tradición del derecho natural. En cuanto jurista y pensador político, Jellinek responde esta cuestión en su obra Die Erklärungen der Menschen und Bürgerrechte. En este ensayo, da respuesta a aquellos que sostenían que la Bill of Rights y la Déclaration des Droits l'Homme et du Citoyen eran la consecuencia lógica de la tradición intelectual del derecho natural, al explicar cómo, por ejemplo, la Bill of Rights -la cual consideraba la "fuente" de la Déclaration des Droits l'Homme et du Citoyen - no era otra cosa que el "producto histórico" de la particular, única, experiencia americana, caracterizada por el desarrollo de pequeñas comunidades de personas que migraron al Nuevo Mundo para profesar sus creencias religiosas libremente (Jellinek, 2002, p. 44).

A pesar de su origen judío, Jellinek estudió a fondo teología cristiana e historia del cristianismo. ${ }^{16}$ Su principal interés fue la historia de la Reforma y el protestantismo. En su ensayo Die Erklärungen der Menschen und Bürgerrechte enfatizó las raíces religiosas de la Bill of Rights en América y la influencia que el espíritu y cultura protestantes tuvieron en la historia de las otrora colonias británicas. Su idea era que algunas libertades fundamentales, incluidas en la Bill of Rights, tenían un origen religioso, principalmente, cristiano (Jellinek, 2002, pp. 44-50).

A través de los años, de acuerdo con Jellinek, los americanos habían creado una sociedad basada en los valores de libertad y emancipación y, cuando se reunieron para establecer un orden político nuevo contra su antigua madre patria, escribieron la Bill of Rights con el objetivo de asegurar la protección de los derechos y libertades que habían experimentado antes de que la revolución contra Inglaterra hubiese estallado (Jellinek, 2002, pp. 44-50).

Por lo que respecta a la Déclaration des Droits l'Homme et du Citoyen, Jellinek destaca la "deuda" que los revolucionarios franceses guardaban a la americana Bill of Rights. Él también denunció a los revolucionarios franceses, quienes -a diferencia de los revolucionarios americanos- se habían inspirado en la tradición del derecho natural y, más exactamente, en Rousseau y su teoría de la volonté générale, al haber empleado el concepto de "soberanía popular" a la realidad política francesa, sin siquiera analizar seriamente si este tipo de concepto podía, o no, ser transformado exitosamente en una institución política funcional.

El pecado de la Revolución francesa ha sido aplicar los muy abstractos, e intrínsecamente absolutistas, conceptos políticos elaborados por la tradición

16 Jellinek se volvió cristiano pocos años antes de su muerte (Kempter, 2005). 
del derecho natural -principalmente por Rousseau-a la realidad francesa; una realidad cuya complejidad, en opinión de Jellinek, iba más allá "de la filosofía del derecho natural". Los revolucionarios americanos triunfaron porque ellos habían establecido sus nuevas instituciones políticas en la experiencia histórica. Los revolucionarios franceses habían fracasado porque buscaban romper radicalmente con el pasado, introduciendo un sistema político completamente nuevo, basado en las ideas y valores que la población no había antes seriamente experimentado.

En otras palabras, bajo la Revolución francesa se transita de un gobierno despótico encarnado por el rey a un gobierno despótico personificado por el pueblo, y el pueblo, como Jellinek destaca, quiere decir el Estado (Jellinek, 2002, pp. 44-50).

Surgen algunas dudas: iexiste alguna conexión entre estos trabajos de 1890 (Hobbes und Rousseau; Die Erklärungen der Menschen und Bürgrrechte) y, verbigracia, el ensayo de Jellinek sobre la Corte Constitucional austriaca? Más aun, iqué podemos aprender sobre la perspectiva política de Jellinek de sus reflexiones sobre el legado revolucionario americano y francés? Primero, estoy convencida de que existe una suerte de continuidad intelectual entre el ensayo de Jellinek de 1885 y el trabajo publicado cuando se encontraba en Alemania. Dicha continuidad consiste en el hecho de que su plan para una Corte Constitucional austriaca y sus escritos sobre, y en contra de, la tradición del derecho natural, Déclaration des Droits l'Homme et du Citoyen, y la comparación entre las revoluciones americana y francesa comparten la convicción de que existe una profunda diferencia entre el buen gobierno y el mal gobierno. Un buen gobierno está basado en una limitación intrínseca del poder, garantías constitucionales y derechos -esto es, en un "espacio de libertad" que debe ser protegido-; mientras que un mal gobierno es lo opuesto; es un gobierno despótico consistente en un tipo de poder ilimitado, y, de acuerdo con Jellinek (1891), este tipo de poder ilimitado puede, a menudo, ser usado en nombre del pueblo (p. 42-44).

Todos los escritos que hasta ahora he discutido contienen claramente elementos de un verdadero punto de vista político liberal clásico, de acuerdo con la definición de liberalismo que ofrecí en el primer parágrafo de este documento. Jellinek enfatizó la importancia de limitar el poder, un concepto elaborado por él, meticulosamente, en Das Recht der Minoritäten.

Ahí, Jellinek dibuja claramente una conexión entre los derechos individuales y los derechos de la minoría: la protección de las minorías dentro y fuera 
de los órganos legislativos era funcional para la protección de los derechos fundamentales. Empero, la protección de las minorías y derechos fundamentales encarnaba un excelente límite al gobierno despótico, y la garantía de los derechos de las minorías e individuos podría prevenir también el proceso de "masificación" y desarrollo del conformismo social, los cuales, en opinión de Jellinek (1898), eran característicos de las sociedades democráticas modernas (pp. 42-44).

Jellinek, directa y francamente, hace referencia a Tocqueville cuando escribe acerca de los riesgos de la masificación y el conformismo social en un sistema democrático. Tocqueville siempre fue uno de los puntos de referencia para el jurista alemán. Al igual que Tocqueville, Jellinek (1898) habló sobre la tiranía de la mayoría y pensaba que una manera eficiente de neutralizar a las mayorías despóticas (dentro y fuera del cuerpo legislativo) era creando y desarrollando un sistema político basado en los derechos fundamentales, derechos de las minorías, límites eficaces al poder, así como la creación y preservación de una sociedad civil participativa (pp. 42-44). Jellinek (1898) concluye su Das Recht der Minoritäten mencionando la Democracy in America de Tocqueville (pp. 46-47).

Existe un lazo común entre el trabajo de Jellinek sobre la Corte Constitucional austriaca, por una parte, y sus escritos publicados en 1890, por la otra. La conexión es su interés en el problema de las minorías y la libertad. Tanto en Austria como en Alemania, Jellinek siempre examinó las vías que permitieran evitar el gobierno despótico.

\section{Algunas reflexiones finales sobre la perspectiva político-liberal de Jellinek}

Si tomamos en consideración la trayectoria intelectual de Jellinek desde 1880 hasta la publicación de Die allgemeine Staatslehere, podemos observar cómo el principio de la limitación del poder fue central y crucial, tanto para su doctrina jurídica como para su perspectiva política (Jellinek, 1900, p. 180).

En términos jurídicos, Jellinek afirmó los pilares del positivismo jurídico, en cuanto elaboró la idea de que el Estado tenía un "carácter sociológico y jurídico." En su opus magnum, Die allgemeine Staatslehre, se distanció a sí mismo de Gerber y Laband. Mientras que Gerber y Laband habían tratado, simplemente, de desarrollar una comprensión legalista del Estado, Jellinek (1900) insistía en los dos lados de la naturaleza del Estado: este debería ser considerado no solo como un constructo jurídico, sino también como un "hecho social" y, en consecuencia, con "funciones jurídicas" y "funciones sociales" (p. 180). 
Los dos lados de la concepción del Estado implicaban una teoría dual. Staatslehre tenía que ser dividida en una "teoría social del Estado" y una "teoría jurídica del Estado" (Jellinek, 1900, p. 180). Desde una perspectiva social, el Estado -como era concebido por Jellinek- se relacionaba con los individuos limitando su propia voluntad y, por tanto, estableciendo derechos fundamentales. Desde su obra System der subjektiven öffentliche Rechte hasta su Allgemeine Staatslehre, Jellinek, continuamente, buscó presentar una idea balanceada del Estado, la cual no lo redujera al "sujeto que manda, y no haya nada más que decir” (Anter, 2014, p. 50). Como Peter M. R. Stirk correctamente subraya:

Su oposición [de Jellinek] a cualquier veneración del poder es evidente en su aproximación al concepto de soberanía, así como en su teoría de la autolimitación del Estado. Jellinek argumentó que el concepto de soberanía era muy a menudo tratado como un llamado al poder irrestricto, anclado en la idea de soberanía como "summum imperium, summa potestas". (2006, p. 22)

Contra el hipostasiar al Estado, Jellinek enfatizó que la soberanía no significa "ausencia de límites", sino más bien la capacidad de autolimitarse (Jellinek, 1900, p. 180). Este continuo marco conceptual, que tomó forma entre 1880 y los albores de 1900, tiene que ser tomado en cuenta al discutir a Jellinek como un pensador político, porque su defensa de los derechos fundamentales y derechos de las minorías está conectada con su idea política y jurídica de la autolimitación del Estado.

Sin embargo, si nos centramos en el punto de vista político de Jellinek, en la forma que ha tomado, a través de sus escritos discutidos hasta ahora, observamos cómo la defensa de los derechos de las minorías y las libertades individuales parecen representar un valor que proteger y preservar per se, porque, como Jellinek afirma en Das Recht der Minoritäten, algunas de las mejores innovaciones de la historia humana fueron iniciadas por las minorías, y las minorías pueden existir y contribuir positivamente al desarrollo de la sociedad solo si los derechos individuales y libertades son garantizadas. Estos derechos y libertades, desde la perspectiva de Jellinek, pueden actuar como un poderoso baluarte contra la masificación y el conformismo (Jellinek, 1898, p. 26). Al mismo tiempo, garantizar los derechos de las minorías representa un tema capital no solo para la sociedad, sino también para el cuerpo legislativo. En ese sentido, podemos comprender mejor cómo, una vez más en Das Recht der Minoritäten, Jellinek 
dedica mucha atención al análisis exhaustivo de la insistencia americana sobre la importancia de la protección de los derechos fundamentales. Esta postura, como Jellinek subraya, está basada en la centralidad de la Constitución, y está caracterizada por la "hipertrofia de la legislación constitucional; desde que una disposición es incluida en el texto constitucional, la minoría parlamentaria cuenta con una herramienta poderosa para prevenir a la mayoría de un abuso de su poder legislativo (Jellinek, 1898, p. 26).

La sensibilidad de Jellinek para los temas de derechos fundamentales y derechos de las minorías podría deberse, en parte, a que él mismo fue parte de una minoría y, también, a los años que pasó en la monarquía austrohúngara, un estado multinacional compuesto por numerosas minorías étnicas. Su experiencia de vida podría haber tenido una influencia en su Weltanschauung, y sus percepciones personales, pero los trabajos mencionados en líneas superiores demuestran claramente cómo detrás del interés de Jellinek en los derechos de las minorías, libertades y derechos fundamentales había un intento constante por entender cómo evitar el gobierno despótico, cómo evitar la tiranía de la mayoría, cómo establecer un Estado constitucional y cómo crear una verdadera "sociedad liberal".

En ese sentido, desde la perspectiva de la historia del pensamiento político, estoy de acuerdo con el distinguido académico europeo de historia del pensamiento político, el italiano Salvo Mastellone (2004), quien decidió, en su libro sobre la Storia del pensiero politico europeo (Historia del Pensamiento Político Europeo), incluir a Jellinek entre los "padres espirituales" del liberalismo europeo del siglo XIX (p. 167).

\section{Referencias}

Anter, A. (2004). Dir normative Kraft des Faktischen: Das Staatsverständnis Georg Jellineks. Nomos Verlag.

Brauneder, W. (1992). Österreichische Verfassungsgeschichte: Einführung in Entwicklung und Struktur. Manzsche Verlag.

Breuer, S. (1999). Georg Jellinek und Max Weber: Von der sozialen zu soziologischen Staatslehre. Nomos Verlag.

Caldwell, P. (1997). Popular Sovereignty and the Crisis of German Constitutional Law: The Theory and Practice of Weimar Constitutionalism. Duke University. 
Constant, B. (1797a). Des effets de la Terreur.

Constant, B. (1797b). Des réactions politiques.

Cornwall, M. (2000). The Undermining of Austria-Hungary: The Battle for Hearts and Minds. MacMillan Press.

Cornwall, M. (2001). The Last Days of Austria-Hungary. University of Exeter Press.

Drüll, D. (2012). Heidelberger Gelehrtenlexikon 1803-1932. Springer Verlag.

Evans, R. J. (1979). Austria, Hungary and the Habsburgs: Central Europe 1683. 1867. Oxford University Press.

Fabbrini, F. (2014). Fundamental Rights in Europe: Challenges and Transformations in Comparative Perspective. Oxford University Press.

Gray, J. (1986). Liberalism. Open University Press.

Healy, M. (2004). Vienna and the Fall of the Habsburg Empire: Total War and Everyday Life in World War I. Cambridge University Press.

Jellinek, G. (1885). Ein Verfassungsgerichtshof für Österreich. Alfred Hölder.

Jellinek, G. (1892). System der subjektiven öffentlichen Rechte (2a ed.).

Jellinek, G. (1898). Das Recht der Minoritäten. Hölder.

Jellinek, G. (1905). Allgemeine Staatslehre. O. von Häring.

Jellinek, G. (1905b). Das System der öffentlichen subjektiven Rechte.

Jellinek, G. (1960). Allgemeine Staatslehre. Wissenschaftliche Buchgesellschaft.

Jellinek, G. (1970). Adam in der Staatsrechtslehre. Vortrag gehalten in der historisch-philosophischen Verein zu Heidelberg (1893). Ausgewählte Schriften und Reden, (1). Scientia Verlag.

Jellinek, G. (1970b). Die Politik des Absolutismus und Radikalismus (Hobbes und Rousseau), Vortrag gehalten in der Aula des Museums zu Basel am 10. Februar 1891. Ausgewählte Schriften und Reden (vol. 1). Scientia Verlag. Jellinek, G. (2002). Le dichiarazioni die diritti dell'uomo e del Cittadino. Laterza. Jounjan, O. (2005). Le pensée juridique en Allemagne. 
Keller, C. (2005). Victor Ehrenberg und Georg Jellinek: Briefwechsel des 19. Jahrhunderts. Vittorio Klostermann.

Kelly, D. (2004). Revisiting the Rights of Man: Georg Jellinek on Rights and State. Law and History Review, 22 (3), 493-529.

Kempter, K. (2005). Die Jellineks 1820-1955: Eine Familienbiographische Studie zum deutschjüdischen Bildungsbürgertum. Droste Verlag.

Kersten, J. (2000). Georg Jellinek und die klassische Staatslehre. Verlag Mohr Siebeck.

Kersten, J. (2011). Georg Jellineks System: Eine Einleitung zu System der öffentlichen subjektiven Rechte. en G. Jellinek, System der subjektiven öffentlichen Rechte. Mohr Siebeck.

Lagi, S. (2012). Hans Kelsen and the Austrian Constitutional Court (19181929). Co-herencia, (16), 273-295.

La Torre, M. (1996). Disavventure del diritto soggettivo: Una vicenda teorica. Giuffrè.

La Torre, M. (2006). La crisi del Novecento: Giuristi e filosofi nel crepuscolo di Weimar. Edizioni Dedalo.

La Torre, M. (2007). Constitucionalism and Legal Theory: A New Paradigm for the Concept of Law. Springer.

Manning, D. J. (1976). Liberalism. J.M. Dent \& Sons Ltd.

Marra, R. (2006). La religione dei diritti: Durkheim, Jellinek, Weber. Giappichelli.

Mastellone, S. (2004). Storia del pensiero politico europeo: Dal XV al XVII secolo. UTET.

Mill, J. S. (1859). On Liberty. John W. Parker.

Palici di Suni, E. (2013). Introduzione a una Corte costituzionale per l'Austria. En G. Jellinek, Una Corte costituzionale per l'Austria. Giappichelli.

Paulson, S. (ed.). (2000). Beiträge zu Leben und Werk. Mohr Siebeck.

Paz, R. (2013). Constructing a Gateway between a Distant God and a Cruel World: The Contribution of German-speaking Scholars to International Law. M. Nijhoff Publishers. 
Plamenatz J. (ed.) (1965). Readings from Liberal Writers: English and French. Everyday Handbooks. Barnes \& Noble Inc.

Quaglioni, D. (1994). Sovranità e autolimitazione (Rileggendo la Dottrina generale dello Stato di G. Jellinek). En M. Basciu (ed.), Crisi e metamorfosi della souranità: Atti del XIX Congresso nazionale della Società italiana di filosofia giuridica e politica. Trento 29-30 settembre 1994. Milán: Giuffrè.

Roshwald, A. (2005). Ethnic Nationalism and the Fall of Empires. Roudledge.

Schönberg, C. (1997). Das Parliament im Anstaltsstaat: Zur Theorie der parlamentarischen Repräsentation in der Staatsrechtslehre des Kaiserreichs (1871-1918). Klostermann.

Sked, A. (1989). The Decline and the Fall of the Habsburg Empire 1815-1918. Longman.

Stirk, P. (2006). Twentieth Century German Political Thought. Edinburgh University Press.

Stolleis, M. (1992). Geschichte des öffentlichen Rechts in Deutschland. Mohr Siebeck.

Stourzh, G. (1994). Ethnic Attribution in Late Imperial Austria: Good and Evil Consequences. En R. Robertson y E. Timms (eds.), The Habsburg Legacy: National Identity in Historical Perspective (pp. 71-74). Edinburgh University Press.

Tocqueville, A. (1835-1840). De la Démocratie en Amérique (2 vols.). C. Gosselin. 